\title{
Eficácia dos tanques de pré-resfriamento na redução de contaminação bacteriana em carcaças de frango ${ }^{1}$
}

\author{
Chilling tanks effectiveness on the reduction of bacterial \\ contamination of poultry carcasses
}

\author{
Juliana Arena Galhardo ${ }^{2 *}$; Melissa Lopes ${ }^{3}$; Juçara Tinasi de Oliveira ${ }^{4}$; \\ Ronaldo Tamanini ${ }^{5}$; Samuel Fabre Sanches ${ }^{6}$; \\ Julio Cesar de Freitas ${ }^{7}$; Ernst Eckehardt Müller ${ }^{8 *}$
}

\section{Resumo}

\begin{abstract}
O objetivo desta pesquisa foi avaliar eficácia dos tanques de pré-resfriamento na redução da contaminação microbiana de carcaças de frango. As amostras foram coletadas de um abatedouro no período de março a setembro de 2005 , totalizando 20 coletas. Foram coletadas amostras de carcaças em três horários representando o início, meio e final do turno matutino de abate sendo 60 amostras ( 20 em cada horário) antes da entrada no pré-chiller e 60 amostras (20 em cada horário) após a saída do chiller. As amostras de frango foram submetidas à pesquisa de coliformes totais (CT), coliformes termotolerantes (CTT), aeróbios mesófilos (AM) e psicrotróficos (MP). A enumeração de CT e CTT foi realizada através da técnica dos tubos múltiplos, a de AM através do sistema Petrifilm ${ }^{\mathrm{TM}} \mathrm{C}$ e a contagem de MP em Agar Padrão para Contagem. As médias mais elevadas do número mais provável de CT e CTT ( $3,83 \log \mathrm{NMP} /$ g e 3,78 $\log \mathrm{NMP} / \mathrm{g}$, respectivamente) e das contagens de AM e MP $(6,61 \log \mathrm{UFC} / \mathrm{g}$ e 4,58 log UFC/g, respectivamente) nas carcaças ocorreram no primeiro horário de coleta, antes da entrada no pré-chiller. Observou-se uma diminuição significativa $(\mathrm{p}<0,05)$ do NMP de CT e CTT e contagem de AM nas carcaças, após a saída dos tanques de resfriamento, no primeiro horário de coleta, indicando que os tanques de pré-resfriamento, no frigorífico estudado, foram eficazes na remoção de microrganismos das carcaças apenas no início dos trabalhos de abate. Não foi detectada a presença de CT e CTT nas amostras de água de abastecimento.
\end{abstract}

Palavras-chave: Coliformes, aeróbios mesófilos, psicrotróficos, qualidade dos alimentos

1 Parte da dissertação de Mestrado da autora principal apresentada ao Programa de Pós-graduação em Ciência Animal da UEL. 2 Mestrado em Ciência Animal, Sanidade Animal / UEL. Endereço: Rua Abaeté, 2567, Jd. Belvedere, Umuarama, PR. CEP: $87505-$ 140. Telefone: (44) 3622-4267 / 8403-3539. E-mail: jugalhardo@gmail.com

3 Mestrado em Ciência Animal, Sanidade Animal / UEL

4 Aluna de Graduação em Medicina Veterinária / UEL

5 Mestrado em Ciência Animal, Sanidade Animal / UEL

6 Professor titular do Departamento de Estatística / CCE / UEL

7 Professor Titular do Departamento de Medicina Veterinária Preventiva / CCA / UEL

8 Professor Titular do Departamento de Medicina Veterinária Preventiva / CCA / UEL. E-mail: muller@uel.br

* Autor para correspondência 


\begin{abstract}
The aim of this research was to evaluate the chilling tanks effectiveness on the reduction of microbial contamination of poultry carcasses from an abattoir, from March to September 2005. Poultry samples were taken in three times, in the beginning, middle and in the end of morning turn, in a total of 60 samples, 20 in each sampling time before the entrance in the chilling tank and other 60 samples, 20 in each sampling time after the exit of the chilling tank. Poultry samples were tested to total coliforms (CT), thermotolerant coliforms (CTT), mesophilic aerobes (AM) and psychrotrophic microorganisms (MP). For CT and CTT research were used the multiple tube fermentation technique, for AM were used Petrifilm ${ }^{\mathrm{TM}} \mathrm{C}$ system and for MP Plate Count Agar. The higher mean of the Most Probable Number of CT and CTT (3,83 $\log$ MPN/g and 3,78 $\log$ MPN/g) and AM and MP counts $(6,61 \log$ UFC/g and 4,58 $\log$ UFC/ g) on poultry carcasses occurred in the first time of sampling, before the entrance in the pre-chiller tank. There was a significant $(\mathrm{p}<0,05)$ decrease on the MPN of CT and CTT and the AM counts on poultry, before the entrance and after the exit of the chilling tanks, in the first sampling time. It is possible to conclude that, in this slaughterhouse, the chilling tanks were effective on the reduction of microbial contamination of poultry carcasses only in the first sampling time. CT and CTT were not found in abattoir water-supply samples.
\end{abstract}

Keywords: Coliforms, mesophilic aerobes, psychrotrophic, food quality

\section{Introdução}

A produção avícola brasileira é bastante expressiva, ocupando a primeira posição no ranking mundial de exportações de carne de frango, à frente dos Estados Unidos, União Européia e China. Entre janeiro e julho de 2005 o Brasil exportou 1.316.232 toneladas de carne de frango in natura, com uma receita superior a US\$ 1,44 bilhões (AVICULTURA INDUSTRIAL ONLINE, 2006; AVISITE, 2006; BRASIL, 2005). Diante da importância econômica e social da carne de frango para o agronegócio nacional, é de extrema importância a adoção de medidas rigorosas de controle da qualidade microbiológica da carne produzida, visando o abastecimento de um mercado cada vez mais exigente e competitivo.

A qualidade microbiológica da carne de frangos pode ser determinada pela condição sanitária das aves ao abate, contaminação durante o processamento, condições de estocagem, distribuição e a comercialização do produto sendo que a maior taxa de contaminação ocorre nas primeiras operações do abate e no tanque de escaldagem (UPTON, 1995; ALMEIDA e SILVA, 1992). A carne de aves é muito suscetível à deterioração devido ao seu elevado teor de nutrientes, à atividade de água elevada e ao $\mathrm{pH}$ próximo à neutralidade, que são fatores favoráveis ao desenvolvimento de microrganismos oriundos da própria ave ou de fontes externas, por essas razões deve ser mantida sob refrigeração ou congelamento (SILVA et al., 2002; BLOOD e JARVIS, 1974).

De acordo com Cason et al. (2000), as carcaças de frango podem estar contaminadas mesmo antes de entrarem na planta de processamento, ou contaminadas por contato com fômites, vísceras, equipamentos, manipulação e pela água da escaldagem. Os microrganismos do grupo coliforme, particularmente os termotolerantes, fazem parte da microbiota intestinal e podem contaminar a carne durante a evisceração (NOTERMANS et al., 1980).

Uma alternativa para a descontaminação de carcaças é a utilização de tanques de préresfriamento (pré-chiller e chiller), que diminuem satisfatoriamente o número de microrganismos contaminantes desde que haja um fluxo de água em quantidade suficiente e contínuo, cloração e manutenção adequada da temperatura da água (BLANK e POWELL, 1995).

O objetivo deste trabalho foi avaliar a eficácia dos tanques de pré-resfriamento sobre a redução da contaminação microbiana de carcaças de frango pela contagem de microrganismos indicadores. 


\section{Material e Métodos}

\section{Coleta das amostras}

As amostras foram coletadas de um abatedouro de aves do norte do Paraná, com abate diário de aproximadamente 30 mil frangos, no período de março a setembro de 2005, em intervalo mínimo de uma semana, totalizando 20 coletas.

Foram coletadas 120 carcaças de frango referentes a dois grupos, um grupo antes da entrada no pré-chiller e outro após a saída do chiller. Os grupos foram constituídos por 60 carcaças, coletadas em três diferentes horários $(6,00 \mathrm{~h} ; 8,15 \mathrm{~h} ; 10,30 \mathrm{~h})$, sendo 20 amostras em cada horário. Os horários propostos representam o início, o meio e o final do abate matutino. O primeiro grupo foi coletado diretamente da nória, antes de cair no pré-chiller e o segundo grupo foi coletado na nória de gotejamento, após a saída do chiller. As amostras foram armazenadas em bags estéreis e mantidas em caixa isotérmica contendo gelo reciclável. O tempo entre a coleta e o processamento das amostras foi de aproximadamente seis horas.

Para a análise da água dos tanques de préresfriamento, com sistema de fluxo em contracorrente, foram colhidas, da mesma forma, 120 amostras nos três horários determinados em cada um dos tanques (pré-chiller e chiller). As 10 amostras da água de abastecimento foram coletadas do reservatório antes do início do abate. Foram coletados $300 \mathrm{~mL}$ de água em vidros de cor âmbar esterilizados contendo $0,2 \mathrm{~mL}$ de tiossulfato de sódio a 10\% (BRASIL, 2004). As amostras foram acondicionadas em caixa isotérmica contendo gelo reciclável e o tempo decorrido entre a coleta e o processamento foi de aproximadamente seis horas.

\section{Aferição de temperatura, cloração e fluxo de água}

A temperatura da água dos dois tanques foi aferida em cada horário de coleta e os níveis de cloro foram verificados no chiller, nos três horários, utilizando os equipamentos do abatedouro (termômetro manual e kit comercial para aferição de cloro a base de ortotoluidina).

O cálculo do fluxo de água (L/carcaça) foi realizado a partir do volume registrado no hidrômetro e incluindo o gelo adicionado pela indústria, em média $840 \mathrm{~L} /$ hora para pré-chiller e $1520 \mathrm{~L} /$ hora para chiller. O gelo do pré-chiller era adicionado manualmente e o do chiller automaticamente, através de uma calha.

\section{Análise microbiológica}

As carcaças foram transportadas ao Laboratório de Microbiologia e Doenças Infecciosas do Departamento de Medicina Veterinária Preventiva da Universidade Estadual de Londrina (DMVP / UEL) e Laboratório de Zoonoses e Saúde Pública DMVP / UEL onde foram realizadas as análises microbiológicas.

O processamento das carcaças seguiu a normatização do Ministério da Agricultura, Pecuária e Abastecimento (BRASIL, 2003). Inicialmente foram removidos assepticamente de cada carcaça $25 \mathrm{~g}$ de pele e músculos das regiões do pescoço, asas e cloaca e acondicionados em bags estéreis de polietileno $\mathrm{Nasco}^{\circledR}$ contendo $225 \mathrm{~mL}$ de água peptonada tamponada a $1 \%\left(\right.$ Biobrás $\left.^{\circledR}\right)$. As amostras foram homogeneizadas em aparelho stomacher por três minutos sendo este conteúdo equivalente à diluição $10^{-1}$. As diluições subseqüentes $\left(10^{-2}\right.$ a $\left.10^{-6}\right)$ foram realizadas em solução salina $0,85 \%$. As amostras de água foram diluídas $\left(10^{0}, 10^{-1}\right)$ em caldo lactosado (Biobrás ${ }^{\circledR}$ ) e as diluições de $10^{-2}, 10^{-3}$ e $10^{-4}$ foram realizadas em água de diluição (tampão fosfato com cloreto de magnésio).

As carcaças foram submetidas à pesquisa de coliformes totais (CT), coliformes termotolerantes (CTT), aeróbios mesófilos (AM) e psicrotróficos (MP). Nas amostras de água de abastecimento foram realizadas determinações de CT e CTT e nas amostras de água dos tanques de pré-resfriamento foram pesquisados CT, CTT e MP. 
Número mais provável de coliformes totais e termotolerantes

Para a determinação do número mais provável (NMP) de CT e CTT das carcaças de frango utilizouse a técnica de tubos múltiplos semeados em caldo lactosado bile verde brilhante 2\% (CLBVB) (Merck $\left.{ }^{\circledR}\right)$ nas diluições $10^{-2}, 10^{-3}$ e $10^{-4}$, em três séries de três tubos para cada amostra. A partir dos tubos positivos após 24 a 48 horas de incubação a $37^{\circ} \mathrm{C}$ (presença de turvação e produção gás) foi transferido $30 \mu \mathrm{L}$ para tubos contendo caldo Escherichia coli (EC) (Vetec $\left.{ }^{\circledR}\right)$ e caldo triptona (Synth ${ }^{\circledR}$ ) que foram incubados a $44,5^{\circ} \mathrm{C}$ por 48 horas em banho-maria. As culturas foram consideradas positivas para $\mathrm{EC}$ e triptona quando apresentaram turvação do meio com produção de gás no caldo EC e formação de anel vermelho após a adição de $0,3 \mathrm{~mL}$ de Reativo de Kovacs no caldo triptona. O resultado foi convertido em $\log _{10}$ e expresso em log NMP/g (BRASIL, 1991/1992).

Para a determinação do NMP de CT e CTT nas amostras de água foi utilizada a técnica de tubos múltiplos como teste presuntivo em caldo lactosado (Biobrás ${ }^{\circledR}$ ), em cinco séries de cinco tubos para cada amostra, nas diluições $10^{0}, 10^{-1}, 10^{-2}, 10^{-3}$ e $10^{-4}$. A partir dos tubos positivos após 48 horas de incubação a $37^{\circ} \mathrm{C}$ (presença de turvação e produção de gás) foram transferidas três alíquotas com alça de Platina dos tubos positivos para tubos contendo CLBVB, que foram incubados em estufa a $37^{\circ} \mathrm{C}$ por até 48 horas, e três alças para tubos contendo caldo $\mathrm{EC}$ incubados a $44,5^{\circ} \mathrm{C}$ por 24 horas em banho-maria (teste confirmativo). As culturas foram consideradas positivas no CLBVB e EC quando apresentaram turvação do meio com produção de gás, o resultado foi convertido em $\log _{10}$ e expresso em NMP/100mL (BRASIL, 1993; BRASIL, 2004).

De acordo com a técnica dos tubos múltiplos, quando todas as diluições se apresentarem positivas o resultado deve ser expresso em "maior que" o valor obtido na tabela. Neste trabalho, as maiores diluições positivas corresponderam a $>4,04 \log \mathrm{NMP} / \mathrm{g}$ nas carcaças de frango e $>5,20 \log \mathrm{NMP} / \mathrm{mL}$ na água.
Para efeito de cálculos e construção de tabelas, 4,04 $\log \mathrm{NMP} / \mathrm{g}$ e 5,20 $\log \mathrm{NMP} / \mathrm{mL}$ foram considerados os valores máximos porém os resultados reais podem ser superiores aos fixados para os cálculos.

\section{Enumeração de aeróbios mesófilos}

A enumeração de AM foi realizada apenas nas amostras de carcaças. Utilizou-se o sistema Petrifilm ${ }^{\mathrm{TM}} \mathrm{AC}$, em conformidade com as orientações do fabricante, nas diluições de $10^{-4}$ e $10^{-6}$, as placas foram incubadas por 48 horas a $35^{\circ} \mathrm{C}$. As contagens foram convertidas em $\log _{10}$ e expressas em log UFC/g.

\section{Enumeração de psicrotróficos}

As contagens de MP das amostras de carcaças foram realizadas utilizando-se as diluições seriadas de $10^{-1}$ a $10^{-5} \mathrm{e}$ para as amostras de água as diluições de $10^{-2}, 10^{-3}$ e $10^{-4}$, foram semeandas $0,1 \mathrm{~mL}$ na superfície do Ágar Padrão para Contagem (PCA) em duplicata (Merck $\left.{ }^{\circledR}\right)$. As placas foram incubadas a $7^{\circ} \mathrm{C}$ por 10 dias, as contagens foram convertidas em $\log _{10}$ e expressas em log UFC/g para amostras de carcaças e $\log$ UFC/mL para amostras de água (BRASIL, 1991/1992).

\section{Análise estatística}

Os dados obtidos foram analisados com a utilização do programa Prism 4.03. Foram empregados ANOVA e teste de Tukey para duas amostras com nível de significância de $5 \%(p<0,05)$.

\section{Resultados e discussão}

A legislação brasileira (BRASIL, 1998) preconiza que a temperatura máxima da água não deve ultrapassar $16^{\circ} \mathrm{C}$ para o pré-chiller e $4^{\circ} \mathrm{C}$ para o chiller. As médias da temperatura da água de préchiller e chiller apresentaram-se em conformidade com a legislação, porém em alguns horários de aferição foram registrados valores acima do 
permitido. As médias de temperatura da água no início, metade e final do abate foram de $10,9^{\circ} \mathrm{C} ; 14^{\circ} \mathrm{C}$; e $15,35^{\circ} \mathrm{C}$ para o pré-chiller e de $4,2^{\circ} \mathrm{C}, 2,90^{\circ} \mathrm{C}$ e $3,45^{\circ} \mathrm{C}$ para o chiller, respectivamente. A temperatura mais alta $\left(12^{\circ} \mathrm{C}\right)$ foi registrada no primeiro horário de coleta da água no chiller, valor este superior ao que determina a legislação.

A média de cloro livre aferido na água do chiller foi de 2,55 ppm, salientando-se que a cloração foi irregular ao longo dos meses de coleta. Nas sete primeiras visitas ao abatedouro, o nível de cloro foi de 0,5 ppm e nas duas últimas os níveis chegaram a 8 e 6 ppm, respectivamente. Trabalhos da década de 60 preconizavam a utilização de elevadas concentrações de cloro, com a justificativa de que 20 ppm de cloro destruiriam patógenos, como a Salmonella, mais rapidamente (WABECK et al. 1968).

De acordo com Blood e Jarvis (1974), o número de coliformes e outros microrganismos podem ser reduzidos quando se utiliza grande quantidade de água e altas quantidades de cloro residual (30 a 50 ppm), mas resultados satisfatórios também podem ser obtidos com a combinação de grande quantidade de água e menor quantidade de cloro residual ( $<5 \mathrm{ppm})$. Níveis elevados de cloro deixam resíduos no alimento e a legislação brasileira (BRASIL, 1998) estabelece o nível de cloro nos tanques em até 5,00 ppm. No frigorífico analisado, os tanques de resfriamento eram do tipo "rosca sem fim" e foi verificada a presença de sujidades na rosca e na parte interna do tanque antes do início do abate, indicando que a higienização foi inadequada. A matéria orgânica acumulada neutraliza a ação do cloro, favorecendo a permanência de microrganismos nesses tanques.

No Brasil, a legislação em vigor (BRASIL, 1998) especifica que a quantidade de água renovada no chiller não deve ser inferior a 1,50L por carcaça (carcaças com peso entre 2,5 e $5,0 \mathrm{Kg}$ ). Os resultados neste estudo estão em desacordo com esta determinação, tendo sido observado o fluxo médio de 1,11L/carcaça no pré-chiller e $0,88 \mathrm{~L} /$ carcaça no chiller.

A média do NMP, de CT e CTT e das contagens de AM e MP presentes nas carcaças de frango antes da entrada no pré-chiller e após a saída do chiller estão representadas nas Figuras 1 e 2.

A média do NMP de CT das carcaças (Figura 1) diminuiu significativamente no primeiro (de 3,83 para 3,03 $\log \mathrm{NMP} / \mathrm{g}$ ) e segundo horário (de 3,71 para 3,09 $\log \mathrm{NMP} / \mathrm{g}$ ) de coleta em relação às contagens antes da entrada no pré-chiller e após saída do chiller. Isto significa que a passagem das carcaças pelos tanques nesses horários foi eficiente na diminuição do NMP de coliformes, porém não houve diminuição significativa no terceiro horário.

Para CTT (Figura 1), houve diminuição significativa da contaminação, após passagem pelos tanques, apenas no primeiro horário de coleta (de 3,78 para $2,86 \log \mathrm{NMP} / \mathrm{g}$ ), sem alterações significativas no segundo e terceiro horário. As contagens máximas de CTT foram bastante elevadas, atingindo valores de 4,04 NMP/g (multiplicação em todas as diluições) nos três horários. Todas as amostras com multiplicação e produção de gás no caldo EC apresentaram produção de indol no caldo triptona, indicando que $E$. coli foi o coliforme predominante.

A média da contagem de AM das carcaças diminuiu significativamente no primeiro horário de coleta $(6,61 \log$ UFC/g antes da entrada nos tanques e 5,58 $\log$ UFC/g após a saída), não ocorrendo decréscimo estatisticamente significativo no segundo e terceiro horário (Figura 2). A maior média da contagem registrada em carcaças antes da entrada no tanque foi 6,61 log UFC/g no primeiro horário e após a saída 5,71 log UFC/g, no terceiro horário. A contagem mínima foi de 4,00 log UFC/g, obtida em carcaças antes da entrada e após a saída do chiller.

A enumeração de MP não sofreu diminuição significativa nos três horários analisados, comparando-se a contaminação das carcaças antes e após a passagem pelos tanques (Figura 2). As médias das contagens de MP antes da entrada no pré-chiller variaram de 3,76 log UFC/g a 4,58 log UFC/g e após a saída do chiller de 3,49 $\log$ UFC/g a $3,93 \log \mathrm{UFC} / \mathrm{g}$. 


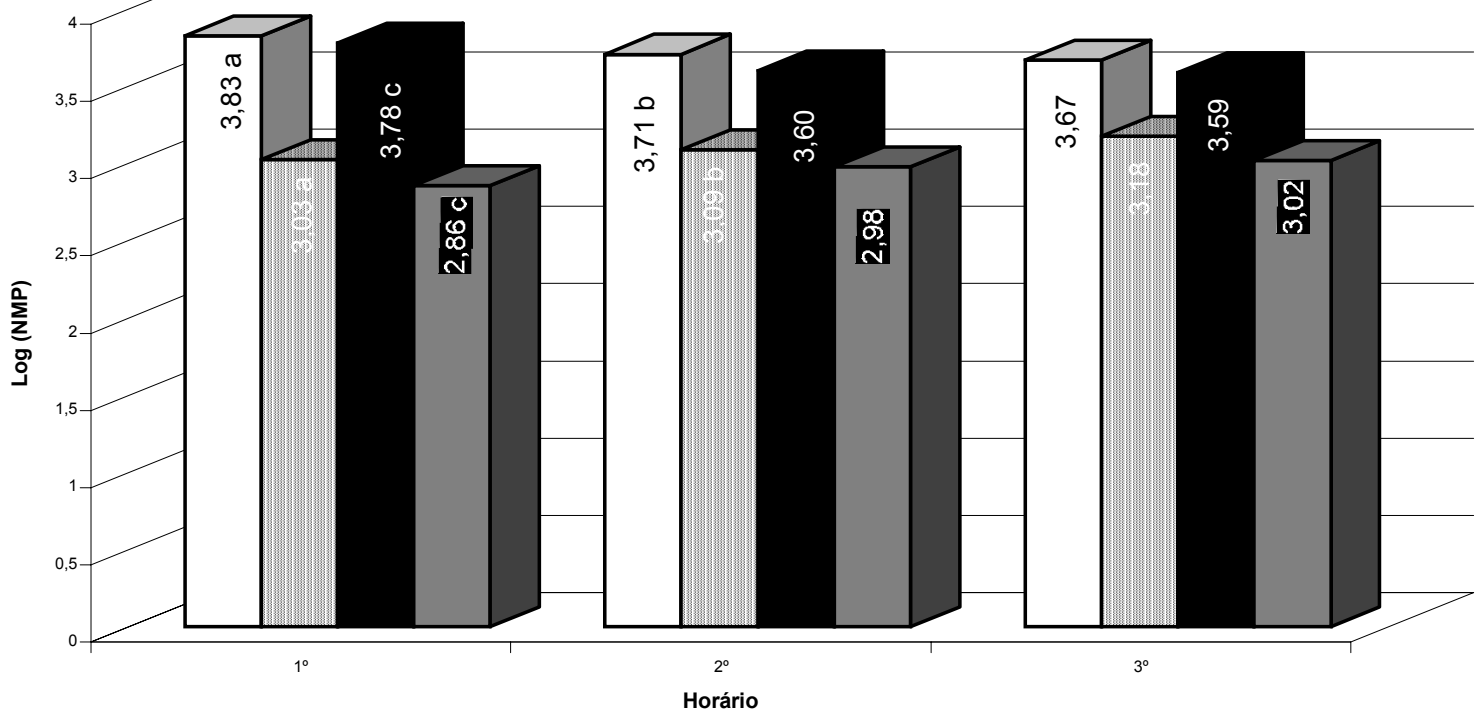

$\square$ Antes (CT) $\quad \square$ Após (CT) $\quad$ Antes (CTT) $\quad \square$ Após (CTT)

Figura 1. Média do número mais provável de coliformes totais (CT) e coliformes termotolerantes (CTT), em log NMP/ g, em carcaças de frango avaliadas antes da entrada no pré-chiller a após a saída do chiller, coletadas no início $\left(1^{\circ}\right)$, meio $\left(2^{\circ}\right)$ e final $\left(3^{\circ}\right)$ do turno matutino de abate de um frigorífico de aves de pequeno porte. Letras iguais representam valores estatisticamente diferentes.

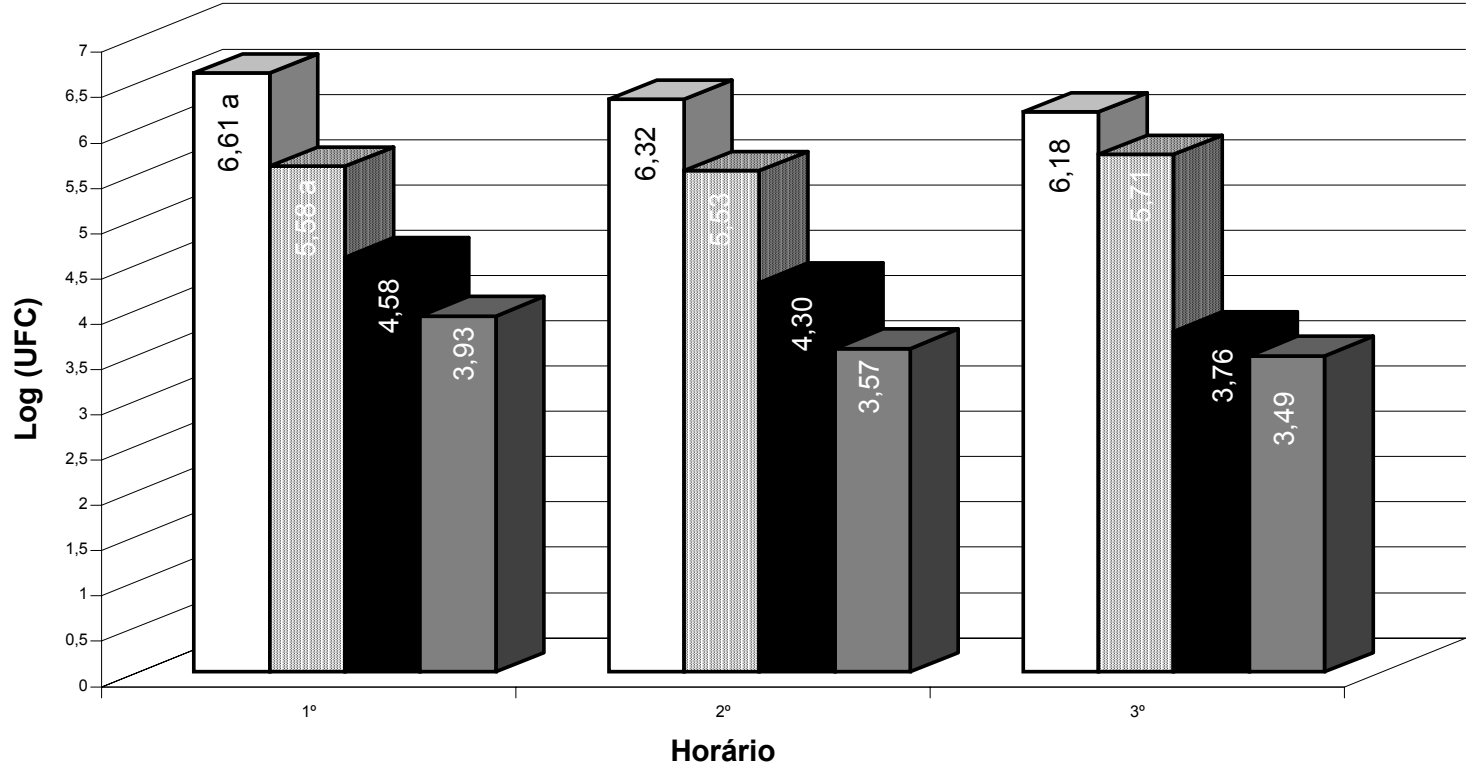

$\square$ Antes (AM) $\quad$ AApós (AM) $\quad$ antes (MP) $\quad$ AApós (MP)

Figura 2. Média da enumeração de microrganismos aeróbios mesófilos (AM) e psicrotróficos (MP), em log UFC/g de carcaças de frango, avaliadas antes da entrada no pré-chiller a após a saída do chiller, coletadas no início $\left(1^{\circ}\right)$, meio $\left(2^{\circ}\right)$ e final $\left(3^{\circ}\right)$ do turno matutino de abate de um frigorífico de aves de pequeno porte.

Letras iguais representam valores estatisticamente diferentes. 
Em todas as análises microbiológicas das carcaças observou-se que as amostras coletadas no primeiro horário antes da entrada no tanque apresentaram altos níveis de contaminação e não foi observada diminuição na contaminação das amostras do terceiro horário.

Estes resultados foram semelhantes aos obtidos por Ritter et al. (2002), que analisaram amostras de tanques de pré-resfriamento de um abatedouro do Rio Grande do Sul e constataram que estes não eram eficazes na redução da contaminação bacteriana por AM e MP. Os autores observaram que os valores relativos ao fluxo de água e a temperatura nos tanques analisados estavam abaixo do estabelecido na legislação, sendo apenas a cloração efetuada de acordo com o recomendado. Neste trabalho o fluxo de água também foi inferior ao preconizado pela legislação vigente, podendo ser um dos fatores responsáveis pela pouca eficiência dos tanques de resfriamento na remoção de microrganismos contaminantes.

A legislação brasileira (BRASIL, 2001) estabelece tolerância máxima para CTT em carnes resfriadas ou congeladas de aves de $10^{4} \mathrm{UFC} / \mathrm{g}$ (equivalente a 4,00 $\log$ UFC/g), na comercialização, porém não estabelece padrões para AM e MP. As médias de CTT observadas (Gráfico 1) podem ser consideradas elevadas, pois as enumerações estão próximas do limite máximo estabelecido na legislação. De acordo com Gill (1998), contagens entre $10^{2}$ a $10^{5} \mathrm{UFC} / \mathrm{cm}^{2}$ de AM indicam condição higiênica satisfatória e as contagens observadas neste trabalho apresentaramse acima deste padrão sugerido. Caso não sejam observadas as condições de transporte e armazenamento adequados a carga microbiana pode atingir níveis elevados podendo comprometer a vida de prateleira do produto final.

Silva et al. (2002) no Brasil, analisaram cortes de carne de aves e verificaram que o microrganismo de maior prevalência foi a $E$. coli. A ocorrência de $E$. coli não patogênicas indica contaminação fecal direta ou indireta e a possibilidade de contaminação por outros microrganismos patogênicos.

Thomson et al. (1975) nos Estados Unidos, analisaram carcaças de frango antes e após a passagem pelos tanques de pré-resfriamento e obtiveram resultados similares a este trabalho, não observando diminuição significativa da contaminação por bactérias da família Enterobacteriaceae e AM. Ueno et al. (1995), em pesquisa no Japão com carne de frango, detectaram $5,0 \times 10^{5}$ coliformes/g e 7,1 $1 \times 10^{6}$ $\mathrm{UFC} / \mathrm{g}$ de $\mathrm{AM}$, contagens superiores às médias obtidas neste trabalho.

Neste estudo as médias observadas na contagem de AM e E. coli nas carcaças de frango foram similares às obtidas por Mead et al. (1982) na Inglaterra. De acordo com estes autores, a média de AM (swab de pele de pescoço) após a saída do chiller foi de 5,92 log.UFC/g. Na pesquisa de enterobactérias foi observado que a $E$. coli foi o coliforme predominante, com incidência de $72 \%$ nas carcaças de frango após a passagem pelo chiller.

Nas Figuras 3 e 4 são apresentados os resultados da análise microbiológica da água proveniente do préchiller e chiller. O NMP de CT e CTT na água diminui significativamente, do pré-chiller para o chiller, no primeiro e segundo horário de coleta. $\mathrm{Na}$ água do chiller as médias de CT e CTT aumentaram do primeiro ao terceiro horário de coleta sendo as médias de CTT de 1,86; 2,49 e 3,85 log NMP/100mL, respectivamente. O NMP máximo de CT no préchiller foi de $\log 5,38$ e no chiller de $\log 5,20$

Não houve diferença significativa entre as contagens de MP da água de pré-chiller e chiller, as médias variaram de 4,32 a 4,49 $\log$ UFC/g e 4,09 a 4,17 log UFC/g na água do pré-chiller e chiller, respectivamente (Figura 4). A água de abastecimento não apresentou contaminação detectável para CT e CTT em nenhuma das 10 amostras estudadas. 


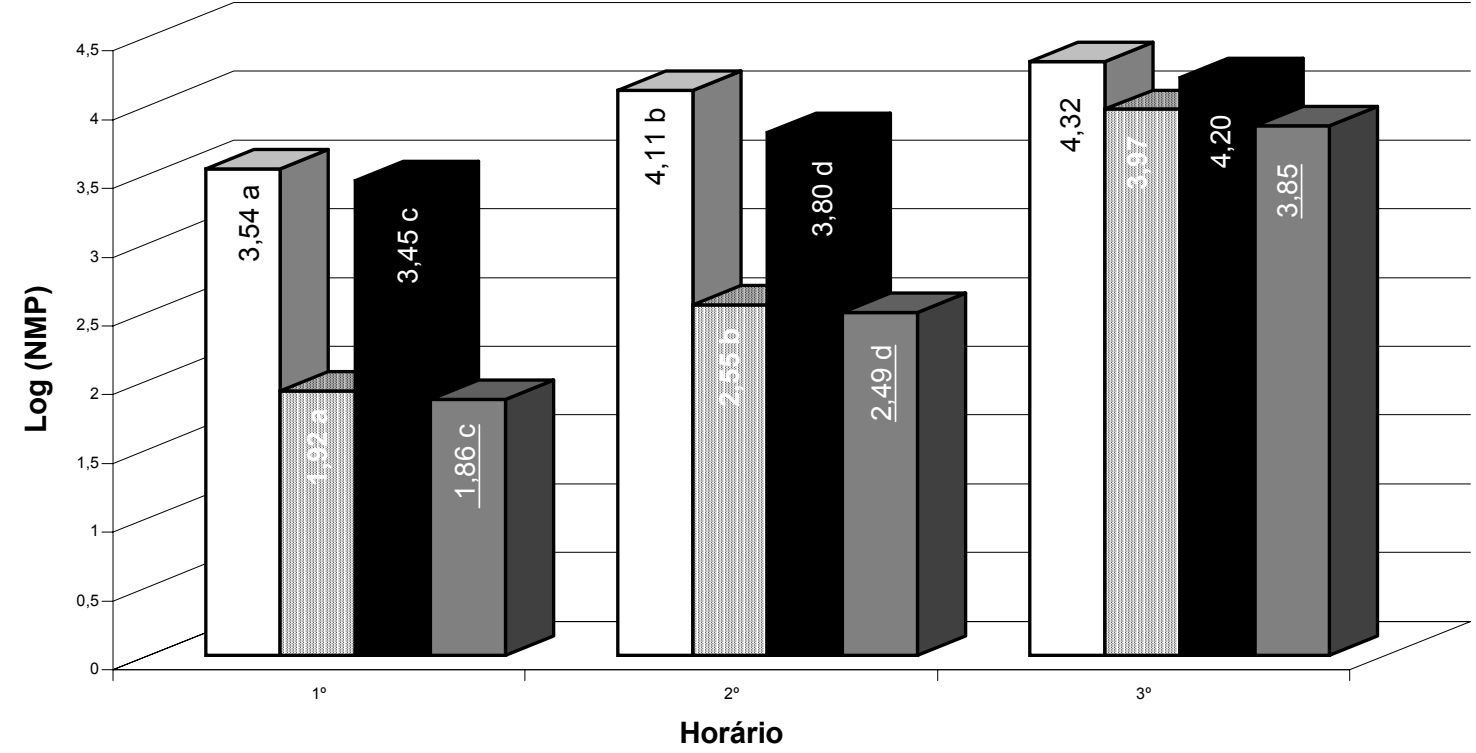

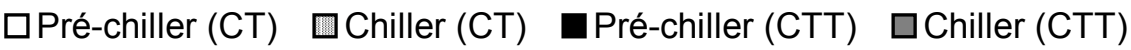

Figura 3. Média do número mais provável de coliformes totais (CT) e coliformes termotolerantes (CTT), em log NMP/100mL, de água proveniente do pré-chiller e do chiller, coletadas no início $\left(1^{\circ}\right)$, meio $\left(2^{\circ}\right)$ e final $\left(3^{\circ}\right)$ do turno matutino de abate de um frigorífico de aves de pequeno porte. Letras iguais representam valores estatisticamente diferentes. Valores em negrito representam valores estatisticamente diferentes. Valores sublinhados representam valores estatisticamente diferentes.

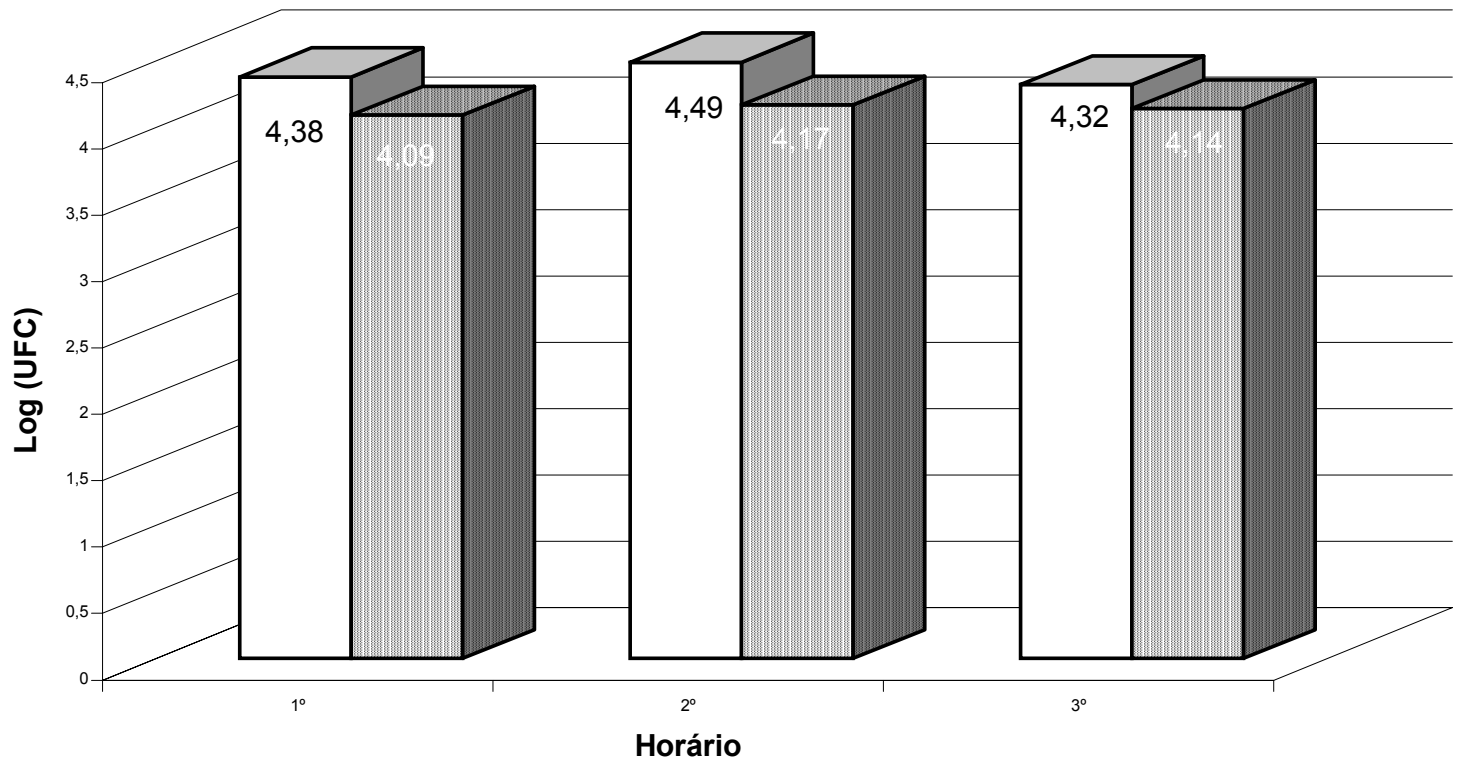

$\square$ Pré-chiller (MP) $\quad \square$ Chiller (MP)

Figura 4. Média da enumeração de microrganismos psicrotróficos (MP), em $\log \mathrm{NMP} / 100 \mathrm{~mL}$, de água proveniente do pré-chiller e do chiller, coletadas no início $\left(1^{\circ}\right)$, meio $\left(2^{\circ}\right)$ e final $\left(3^{\circ}\right)$ do turno matutino de abate de um frigorífico de aves de pequeno porte. 
No terceiro horário de coleta não houve nenhuma diminuição significativa da contaminação, sendo este dado semelhante à análise das carcaças. $\mathrm{O}$ aumento da contaminação por CT e CTT, verificada ao longo dos horários na água, não foi observada nas carcaças. Isto pode ser explicado pela remoção parcial de microrganismos das carcaças por ação mecânica e conseqüente liberação para a água dos tanques.

Thomson et al. (1975) afirmam que os tanques de imersão, quando usados apropriadamente e com renovação adequada de água, podem reduzir a contaminação bacteriana das carcaças. Blank e Powell (1995), no Canadá, constataram que a passagem pelos tanques de pré-resfriamento é capaz de reduzir as contagens bacterianas das carcaças, porém esta redução pode ser pequena em relação ao número de bactérias remanescentes nas carcaças.

Soares et al. (2005) pesquisaram CT e E. coli em amostras de água de vários pontos de um frigorífico de Itatiba, SP, utilizando substrato cromogênico (Colilert) e não encontraram coliformes na água do tanque de resfriamento, indicando que no frigorífico analisado o sistema de higienização era bastante eficaz. Smith et al. (2005), em trabalho realizado nos Estados Unidos, afirmaram que os tanques de pré-resfriamento, mesmo sem higienização adequada, sem renovação constante de água e sem adição de cloro são eficientes na redução do número de bactérias das carcaças, inclusive patógenos. Mesmo em condições extremas de contaminação os autores observaram que em 40\% das carcaças contaminadas, direta ou indiretamente com fezes, o número de CT e E. coli não aumentou.

Os resultados obtidos por Soares et al. (2005) e Smith et al. (2005) são contrários à realidade observada neste trabalho. Embora tenha ocorrido a eficiência dos tanques de pré-resfriamento na remoção dos microrganismos das carcaças de frango no primeiro horário de coleta, a contaminação das carcaças e da água do pré-chiller e chiller pode ser considerada bastante elevada, observando-se em alguns períodos de coleta o aumento na contaminação. Estes fatos podem ser explicados pela contaminação elevada das carcaças antes do préresfriamento, fluxo de água insuficiente, cloração inadequada e temperatura da água dos tanques acima das preconizadas em algumas aferições.

De acordo com os resultados observados, os tanques de pré-resfriamento não foram considerados eficientes na descontaminação de carcaças de frango no abatedouro estudado.

\section{Referências}

ALMEIDA, P. F.; SILVA, E. N. Estudos sobre o controle e disseminação bacteriana em carcaças de frangos de abatedouros industriais. Arquivo Brasileiro de Medicina Veterinária e Zootecnia, v.44, n.2, p.105-120, 1992.

AVICULTURA INDUSTRIAL ONLINE. Embargo à carne afeta exportação: aftosa e gripe aviária prejudicam os negócios do setor. Revista Avicultura Industrial Online, mar. 2006. Disponível em: http:// www.aviculturaindustrial.com.br/site/ dinamica.asp?id $=18902 \&$ tipo $\_$tabela $=$negocios\&categoria $=$ exportacao Acesso em 17 abr. 2006.

AVISITE. Exportação mundial de frango cresce 5,5\% em 2006, prevê USDA. AviSite, mar. 2006. Disponível em: http:/ / w w w. a visite.com.br/noticia s/ default.asp?CodNoticia=6613. Acesso em 17 abr. 2006.

BLANK, G.; POWELL, C. Microbiological and hydraulic evaluation of immersion chilling for poultry. Journal of Food Protection, v.58, n.12, p.1386-1388, 1995.

BLOOD, R. M.; JARVIS, B. Chilling of poultry: the effects of process parameters on the level of bacteria in spinchiller waters. Journal of Food Technology, v.9, n.2, p.157169, 1974.

BRASIL. Ministério da Agricultura, Pecuária e Abastecimento. Exportação do Agronegócio Brasileiro. Carne de Frango in natura, janeiro a junho de 2005. Disponível em:

http://www.agricultura.gov.br/pls/portal/url/ITEM/ C90C773459F9B52AE0300801FD0AF827. Acessado em 17 abr. 2006.

BRASIL. Ministério da Saúde. Fundação Nacional de Saúde. Manual Prático de Análise de Água. Brasília: Fundação Nacional de Saúde, 2004. 146p. 
BRASIL. Ministério da Agricultura, Pecuária e Abastecimento. Instrução Normativa no. 62 de 26 de agosto de 2003. Métodos analíticos oficiais para análises microbiológicas para controle de produtos de origem animal e água. Diário Oficial da União, Brasília, DF, 18 set. 2003. Seção 1

BRASIL. Resolução RDC ANVISA/MS nº. 12, de 02 de janeiro de 2001. Regulamento Técnico sobre os Padrões Microbiológicos para Alimentos. Diário Oficial da União, Brasília, DF, 10 jan. 2001. Seção 1.

BRASIL. Portaria no. 210 de 10 de novembro de 1998. Regulamento técnico da inspeção tecnológica e higiênicosanitária de carne de aves. Diário Oficial da União, Brasília, DF, 26 nov. 1998. Seção 1.

BRASIL. Ministério da Agricultura, Pecuária e Abastecimento. Portaria no. 101 de 11 de agosto de 1993. Aprova e oficializa os métodos analíticos para controle de produtos de origem animal e seus ingredientes, métodos biológicos (anexo) determinando seu emprego em todas as atividades desenvolvidas pela rede oficial do sistema coordenado pela Coordenação Geral de Laboratório Animal - CGLA do Departamento de Defesa Animal. Diário Oficial da União, Brasília, DF, 17 agost. 1993. Seção 1.

BRASIL. Ministério da Agricultura, Abastecimento e da Reforma Agrária. Métodos de Análise Microbiológica para Alimentos. 2ed. Brasília, 1991/1992.

CARVALHO, A. C. F. B.; FLORIOTO, J. F.; PEREIRA, G. T.; SCHOCKEN-ITURRINO, R. P. Avaliação microbiológica da carne de ave mecanicamente separada (CAMS). Revista Higiene Alimentar, v.16, n.98, p.91-100, 2002.

CASON, J. A.; HINTON JR, A.; INGRAM, K. D. Coliform, Escherichia coli and salmonellae concentrations in a multiple-tank, counterflow poultry scalder. Journal of Food Protection, v.63, v.9, p.1184-1188, 2000.

GILL, C. O. Microbiological contamination of meat during slaughter and butchering of cattle, sheep and pigs. In. DAVIES, A. e BOARD, R. The Microbiology of Meat and Poultry. 15ed,[S.1.], 1998. p.118-154.

MEAD, G. C.; ADAMS, B. W.; HAQUE, Z. Studies on the incidence, origin and spoilage potencial of psychrotrophic Enterobacteriaceae occurring on processesd poultry. Fleischwirtsch, v.62, n.9, p.1140-1144, 1982.
NOTERMANS, S.; TERBIJHE, R. J.; VAN SCHOTHORST, M. Removing faecal contamination of broilers by spraycleaning during evisceration. British Poultry Science, v.21, p.115-121, 1980 .

RITTER; R.; BERGMANN, G. P. Eficácia do sistema de pré-resfriamento de frangos em tanques, sobre a redução da contaminação bacteriana de carcaças. Revista Higiene Alimentar, v.17, n.108, 2002.

SILVA, J. A..; AZERÊDO, G. A.; BARROS, C. M. R.; COSTA, E. L.; FALCÃO, M. M. S. Incidência de bactérias patogênicas em carne de frango refrigerada. Revista Higiene Alimentar, v.16, n.100, p.97-101, 2002.

SMITH, D. P.; CASON, J. A.; BERRANG, M. E. Effect of fecal contamination and cross-contamination on numbers of coliform, Escherichia coli, Campylobacter and Salmonella on immersion-chilled broiler carcasses. Journal of Food Protection, v.68, n.7, p.1340-1345, 2005.

SOARES, M. M. S. R.; REZENDE, A.C. B.; SREBERNICH, S. M. Análise microbiológica da água utilizada em diversas etapas do abate de aves. In: CONGRESSO BRASILEIRO DEMICROBIOLOGIA, 23, 2005, Santos. Anais... CDROM.

THOMSON, J. E.; COX, N. A.; WHITEHEAD, W. K..; MERCURI, A. J.; JUVEN, B. J. Bacterial counts and weight changes of broiler carcasses chilled commercially by water immersion and air-blast. Poultry Science, v. 54, p.14521460, 1975.

UENO, H.; USUKU, T.; MATSUBA, S.; KAWAI, K.; OHTA, T.; TASAKA, T.; MORTA, C. A. Bacterial survey of raw chicken meat retail shops in Ebetsu City from 1987 to 1992. Journal of Japan Medical Association, v.48, n.4, p.281-284, 1995.

UPTON, M. Relationships between pathogen growth and the general microbiota on raw and processed meat and poultry. Journal of Food Safety, v.15, n.2, p.133-144, 1995.

WABECK, C. J.; SCWALL, D. V.; EVANCHO, G. M.; HECK, J. G.; ROGERS, A. B. Salmonella and total count reduction in poultry treated with sodium hypochlorite solutions. Poultry Science, v.47, n.4, p.1090-1094, 1968. 